\title{
Persistence of Opioid Prescribing after a Forearm or Lower Leg Fracture
}

\author{
Ning N. Yu, PhD 1,2 , Chao Zhou, PhD ${ }^{3}$, Curtis Florence, $P h D^{4}$, and Jan L. Losby, PhD ${ }^{4}$ \\ ${ }^{1}$ Nanjing Audit University, Nanjing, China; ${ }^{2}$ Rural Education Action Program, Freeman Spogli Institute for International Studies, Stanford University, \\ Stanford, CA, USA; ${ }^{3}$ Health Care Cost Institute, Washington, DC, USA; ${ }^{4}$ National Center for Injury Prevention and Control, Centers for Disease Control \\ and Prevention (CDC), Atlanta, GA, USA.
}

KEY WORDS: opioid-naïve; prescription opioid analgesics; chronic pain management.

J Gen Intern Med 33(3):251-2

DOI: $10.1007 / \mathrm{s} 11606-017-4214-8$

(C) Society of General Internal Medicine 2017

\section{INTRODUCTION}

Understanding the relationship between opioid treatment for acute pain and subsequent long-term use is necessary to inform clinical decisions on pain treatment. Previous research has described long-term opioid use after treatment for acute pain in postoperative and fragility fracture treatment. ${ }^{1-3}$ We carefully examined the association between forearm and lower leg fractures in 2011 and opioid prescription in 2011-2014 among disabled Medicare beneficiaries who did not have opioid prescriptions in 2010 . We focused on forearm and lower leg fractures because these injuries to major long bones not directly connected to the torso have limited long-term health consequences and are less likely to cause health complications.

\section{METHODS}

We utilized the complete files of the 2010-2014 Medicare claims data from the Centers for Medicare and Medicaid Services (CMS). Starting with all Medicare beneficiaries under the age of 65 in 2010 who entered Medicare through the Social Security Disability Insurance program for the medically disabled, we selected individuals covered continuously for 60 months in Parts A, B, and D from 2010 to 2014. Opioid use was defined as any kind of opioid prescription identified from the Centers for Disease Control and Prevention's (CDC) compilation of opioid formulations, based on the National Drug Code (NDC) classification system. ${ }^{4} \mathrm{We}$ selected opioid-naïve patients (those without any opioid prescription records in 2010). We excluded beneficiaries enrolled in any managed care programs that did not report detailed claims data to CMS and individuals with records of cancer treatment, palliative care, or end-oflife care.

The study population comprised three groups: group 1 -those with forearm fractures (ICD9-CM diagnosis code 813 , fracture of radius and ulna) in 2011 but no other fracture record (800-829) during the period 20102014; group 2-those with lower leg fracture (823, fracture of tibia and fibula) in 2011 but no other fracture record; and group 3-those without any fracture record.

We conducted separate linear regressions of the probability of opioid prescription in 2011-2014 after forearm and leg fractures in 2011, controlling for various demographic and health status variables: age, gender, race/ethnicity, income, county of residence, and 2010 health status (15 conditions from the Charlson comorbidity index).

\section{RESULTS}

Group 1 included 1465 individuals, group 2 included 758, and group 3 included 957,856. The average ages for groups 1, 2, and 3 were $53.7,53.2$, and 52.4 years, respectively, and men accounted for $53.9 \%, 46.2 \%$, and $42.3 \%$ of individuals in the three study groups.

In 2011, the percentage of individuals with recorded opioid prescriptions varied by group: group, $163.3 \%$; group 2, $58.6 \%$, and group 3, $17.5 \%$ (Fig. 1). After 2011, the percentages in groups 1 and 2 differed from that in group 3 by around $7 \%$. For example, in 2014, 26.7\% of group 1 and $26.4 \%$ of group 2 recorded opioid prescriptions, in contrast to $19.4 \%$ in group 3.

Differences among the three groups in those who had continuous opioid records from 2011 to 2014 can explain the almost parallel gaps in Figure 1. Indeed, 9.08\% of group 1 and $10.16 \%$ of group 2 had opioid prescriptions for 4 consecutive

Published online November 20, 2017 


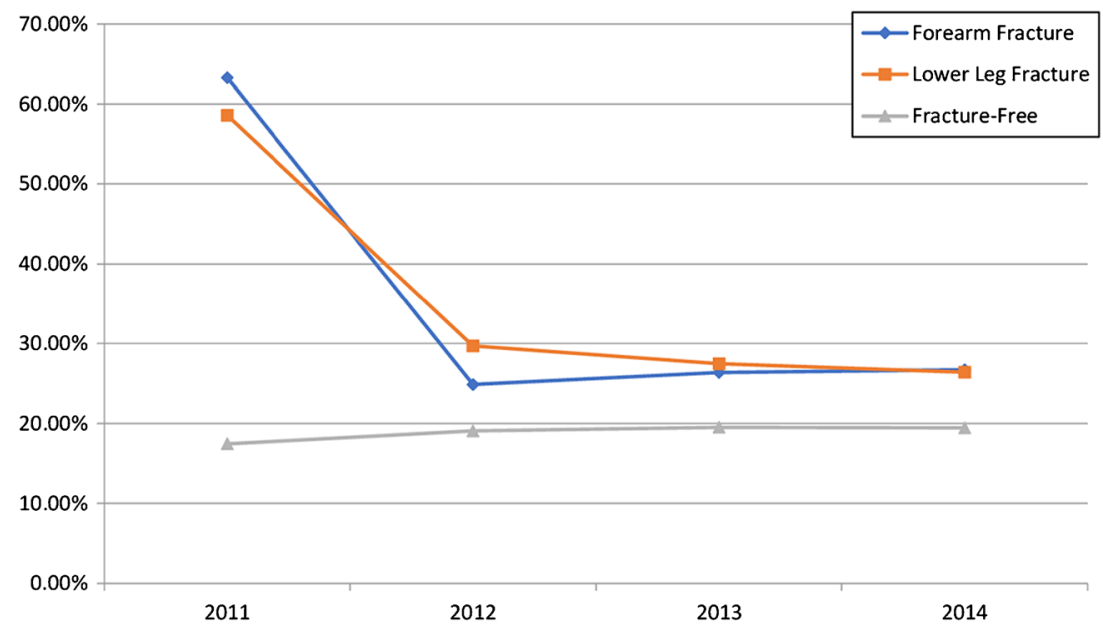

Figure 1 Proportion of Medicare beneficiaries with an opioid prescription by fracture status, United States 2011-2014.

years, compared with $3.56 \%$ for group 3. Long-term opioid users (with 6 or more opioid prescriptions in 2014) accounted for $47.37,48.05$, and $48.44 \%$, respectively.

A forearm fracture in 2011 increased the chance of an opioid prescription in 2014 by $5.5 \%$, and a lower leg fracture increased the chance by $6.1 \%$ (Table 1 ), after controlling for other factors. Descriptive and linear regression results pointed to similar findings: a fracture in 2011 increased the chance of an opioid prescription in 2014 by $5-8$ percentage points.

\section{DISCUSSION}

More than half of opioid-naïve patients with forearm or lower leg fractures in 2011 received opioid prescriptions that year. Over the next 3 years, these patients remained significantly more likely to have opioid prescriptions than those without fractures, which could not be explained by demographic or non-fracture health status. The analysis did not precisely

Table 1 Linear Least Squares (LLS) Regression Results for 2011 Fracture and 2011-2014 Opioid Prescription, Medicare Beneficiaries (USA)

\begin{tabular}{lllll}
\hline \hline $\begin{array}{l}\text { Body part location of the } \\
\text { fracture }\end{array}$ & \multicolumn{3}{l}{$\begin{array}{l}\text { Coefficients of the regression } \\
\text { by year of opioid prescription }\end{array}$} \\
\cline { 2 - 5 } & $\mathbf{2 0 1 1}$ & $\mathbf{2 0 1 2}$ & $\mathbf{2 0 1 3}$ & $\mathbf{2 0 1 4}$ \\
\hline Forearm & 0.436 & 0.041 & 0.050 & 0.055 \\
Lower Leg & 0.397 & 0.097 & 0.070 & 0.061 \\
\hline
\end{tabular}

The numbers reported in the table are coefficient results for eight separate LLS regressions. Whether an individual was prescribed opioids in 2011-2014 is a dependent variable; whether an individual had a certain type of fracture in 2011 is an independent variable. The first row shows the results of forearm fractures in 2011 as an indicator of opioid prescription in 2011-2014, based on LLS regression with the forearm fracture and fracture-free populations together; the second row shows the effects of lower leg fracture in 2011 based on regressions with the lower leg fracture and fracture-free populations together. These regressions all controlled for age, age squared, gender, racelethnicity, proxy for income (Part D cost-sharing information), health status (15 comorbid conditions in 2010, including heart disease and diabetes, as used in the Charlson comorbidity index), and county of residence. For all estimates, p-values based on standard errors are less than 0.0001 capture the timing of opioid utilizations after the fracture, and the results cannot be generalized beyond a medically disabled population. Nonetheless, this paper provides evidence that over one-quarter of formerly opioid-naïve patients were prescribed opioids sometime in the 3 years after fracture. The persistence of opioid prescribing suggests a need for more effective post-fracture pain management that follows evidence-based opioid prescribing guidelines. ${ }^{5}$

Acknowledgements: We thank Mick Ballesteros, $P h D(C D C)$, Tamara Haegerich, $P h D(C D C)$, Karin Mack, $P h D(C D C)$, and Rita Noonan, $P h D$ (CDC), who provided helpful comments but were not compensated.

Corresponding Author: Chao Zhou, $\mathrm{PhD}$; Health Care Cost Institute, Washington, DC, USA (e-mail: czhou@healthcostinstitute.org).

\section{Compliance with Ethical Standards:}

Conflict of Interest: All authors declare that they have no conflict of interest.

Disclaimer: Chao Zhou was an economist at the National Center for Injury Prevention and Control, Centers for Disease Control and Prevention, Atlanta, Georgia, at the time this study was conducted. She is now a Pharmacoeconomics Research Fellow at the Health Care Cost Institute in Washington, $D C$.

The findings and conclusions in this report are those of the authors and do not necessarily represent the official position of the Centers for Disease Control and Prevention, Health Care Cost Institute, or Stanford University.

\section{REFERENCES}

1. Sun EC, Darnall BD, Baker LC, et al. Incidence of and risk factors for chronic opioid use among opioid-naive patients in the postoperative period. JAMA Intern Med. 2016;176(9):1286-93.

2. Munson JC, Bynum JW, Bell J, et al. Patterns of prescription drug use before and after fragility fracture. JAMA Intern Med. 2016;176(10):1531-8.

3. Shah A, Hayes CJ, Martin BC. Characteristics of initial prescription episodes and likelihood of long-term opioid use-United States, 20062015. MMWR Morb Mortal Wkly Rep. 2017;66:265-9.

4. CDC. CDC compilation of opioid analgesic formulations with morphine milligram equivalent conversion factors, 2014 version. Available at: http:// www.pdmpassist.org/pdf/BJA_performance_measure_aid_MME_conversion.pdf. Accessed 16 Oct 2017.

5. Dowell D, Haegerich TM, Chou R. CDC guideline for prescribing opioids for chronic pain-United States, 2016. JAMA. 2016;315(15):1624-45. 